\title{
The Effect of Dietary Supplementation of Green Tea Catechins on Cardiovascular Disease Risk Markers in Humans: A Systematic Review of Clinical Trials
}

\author{
Sarah O. Lau ${ }^{1, \dagger}{ }^{\dagger}$ Ekavi N. Georgousopoulou 1,2, ${ }^{\dagger}$, Jane Kellett 1,3 , Jackson Thomas 1,3, \\ Andrew McKune ${ }^{1,4,6}$, Duane Mellor ${ }^{1,3}$, Paul D. Roach ${ }^{1,5}$ and Nenad Naumovski ${ }^{1,3,5, *}$ \\ 1 Faculty of Health, University of Canberra, Canberra ACT 2601, Australia; \\ u3137160@uni.canberra.edu.au (S.O.L.); ekavi@hua.gr (E.N.G.); jane.kellett@canberra.edu.au (J.K.); \\ jackson.thomas@canberra.edu.au (J.T.); andrew.mckune@canberra.edu.au (A.M.); \\ duane.mellor@canberra.edu.au (D.M.); paul.roach@newcastle.edu.au (P.D.R.) \\ 2 Department of Nutrition-Dietetics, School of Health and Education, Harokopio University of Athens, \\ Athens 17671, Greece \\ 3 University of Canberra Health Research Institute (UCHRI), Canberra ACT 2601, Australia \\ 4 University of Canberra Research Institute for Sport and Exercise (UCRISE), Canberra ACT 2601, Australia \\ 5 School of Environmental and Life Sciences, University of Newcastle, Ourimbah NSW 2258, Australia \\ 6 Discipline of Biokinetics, Exercise and Leisure Sciences, School of Health Sciences, \\ University of KwaZulu-Natal, Durban, KwaZulu-Natal 4000, South Africa \\ * Correspondence: nenad.naumovski@canberra.edu.au; Tel.: +61-262-068-719 \\ + These authors contributed equally to this work.
}

Academic Editor: Quan V. Vuong

Received: 29 April 2016; Accepted: 10 June 2016; Published: 21 June 2016

\begin{abstract}
Green tea catechins (GTCs) are secondary plant metabolites that have been associated with health benefits in human trials. As such, they have the potential to reduce cardiovascular disease (CVD) risk; however, results are not consistent. This systematic review of the published data assessed the putative effect of GTCs supplementation on anthropometric, blood pressure, and biochemical measures associated with CVD risk. It was conducted in accordance with the preferred reporting items for systematic reviews and meta-analyses (PRISMA) guidelines exploring four major electronic databases (MEDLINE, Cochrane Library, Web of Science, and Scopus). Studies were included if they were published in peer-reviewed journals in English from 1990 until October 2015, and were human double-blind randomized and placebo-controlled trials (RCTs). From 122,428 articles initially identified, after two levels of screening, seven studies met the inclusion criteria. The review revealed consistent and significant $(p \leqslant 0.05)$ reductions in body mass index (BMI), blood pressure and plasma lipids; however, this effect would have been less if between-group effects had been considered. The current evidence base also has considerable methodological limitations due to suboptimal statistical methods used in data analyses. Future research efforts must aim to rectify this paucity of evidence with well-designed and well-reported prospective studies.
\end{abstract}

Keywords: green tea catechins; GTCs; epigallocatechin gallate; EGCG; systematic review; human clinical trials; cardiovascular disease biomarkers

\section{Introduction}

Cardiovascular disease (CVD) affects the blood vessels through atherosclerotic damage and is responsible for 17.5 million deaths per year, representing $31 \%$ of all deaths worldwide $[1,2]$. Cardiovascular disease risk is predominantly associated with increased or altered lipid concentrations, raised blood pressure, and smoking, which cause atherosclerotic plaque accumulation [3]. 
Subsequently, individuals at high risk of developing CVD are often diagnosed with dyslipidemia and/or hypertension [3]. Dyslipidemia is defined as having a plasma triglyceride (TG) content of greater than $1.7 \mathrm{mmol} / \mathrm{L}$, total cholesterol (TC) content of greater than $5.2 \mathrm{mmol} / \mathrm{L}$, low density lipoprotein cholesterol (LDL-C) content of greater than $3.5 \mathrm{mmol} / \mathrm{L}$, and a high density lipoprotein cholesterol (HDL-C) content of less than $1.0 \mathrm{mmol} / \mathrm{L}$ for males and less than $1.2 \mathrm{mmol} / \mathrm{L}$ for females [4]. These biochemical abnormalities are commonly identified in type 2 diabetes mellitus and metabolic syndrome, which are also associated with increased CVD risk [5]. Hypertension is defined as having a systolic blood pressure at or above $140 \mathrm{mmHg}$, and/or a diastolic blood pressure at or above $90 \mathrm{mmHg}$ [4]. It has a global prevalence of approximately $22 \%$ in adults [6] and it is a risk factor for $\mathrm{CVD}$, including coronary heart disease and stroke, as it exacerbates atherosclerotic pathogenesis, clot formation, and narrowing and weakening of the blood vessels, which become more likely to occlude or hemorrhage, causing ischemia $[3,6]$. Other features related to increased CVD risk are hyperglycemia (fasting plasma glucose $>5.6 \mathrm{mmol} / \mathrm{L}$ ), oxidation of LDL, inflammation, and pro-thrombotic conditions.

CVD is a multifactorial chronic condition and its progression is accelerated through specific behavioral and lifestyle factors such as obesity, sedentary lifestyle, and unhealthy dietary habits [7]. Obesity is commonly associated with CVD pathogenesis, as it is known to induce insulin resistance, low grade inflammation, endothelial dysfunction, and subsequent atherosclerotic development [8]. Anthropometric data refers to physical measurements of the body, with height, weight, waist circumference (WC), and body mass index (BMI) being the primary anthropometric outcomes measured in clinical practice and trials, and, as such, they will be used in this systematic review [9-15]. Overweight and obesity are defined as an abnormal or excessive fat accumulation in the body, which may have the potential to negatively affect individuals' health [7]. These conditions are defined as having a BMI of greater or equal to $25.0 \mathrm{~kg} / \mathrm{m}^{2}$ and $30 \mathrm{~kg} / \mathrm{m}^{2}$, respectively [16].

Current evidence suggests that a healthy dietary pattern is favorable in protecting against CVD. What still remains controversial is whether it is whole dietary patterns that offer this protection or whether it is specific foods (e.g., a high intake of fiber-rich plant foods, legumes, and fish, and a low intake of processed and saturated-fat-rich foods) and beverages (e.g., wine, coffee, and tea), or their components which are responsible for the protective effect. Most of the data supporting whole diet and food effects are from ecological studies and observational data. Whilst such studies can provide information on hard endpoints of myocardial infarctions and death, due to methodological limitations, such studies only show correlation, not causation. Clinical trials can assess causality, and can examine the health benefits of individual foods or dietary supplements, such as green tea (GT) in reducing the risk for developing CVD. However, often due to limitations in study length, they can usually only reveal effects on biomarkers of CVD risk.

Tea (all forms) is a traditionally consumed beverage originating from ancient China, and has been popular for over 4000 years $[17,18]$. It is the second most commonly consumed drink after water globally, well ahead of other beverages such as coffee, beer, wine, and soft drinks [17,19]. It is estimated that between 2.5 to 3 million $\mathrm{kg}$ of tea is produced annually worldwide. Accounting for $20 \%$ of the total tea production [20,21], GT is consumed predominantly in Asian countries and Morocco, but its popularity has also increased in Western countries over the last three decades [17]. In the United States, the sales of GT were approximately $\$ 230$ million, revealing its popularity [22]. Favorable effects on human health were first detailed in traditional Chinese medicine, which encouraged the use of GT for body ailments, such as pain, for improved digestion, detoxification and body energy levels and to generally lower mortality rates from disease [17]. The beneficial effects of GT consumption in reducing CVD risk is mainly attributed to the green tea catechins (GTCs), some of the many constituents present in green tea [17-21].

The GTCs are plant secondary metabolites, with a very strong antioxidant capacity, produced in the leaves of the tea plant Camellia sinensis [18]. The approximate leaf dry weight composition of GT includes $30 \%-40 \%$ polyphenols, $26 \%$ fibers, $15 \%$ proteins, $2 \%-7 \%$ lipids, $5 \%$ vitamins and minerals, 
$3 \%-4 \%$ methylxanthines (mainly caffeine), and $1 \%-2 \%$ pigments. Catechins account for $80 \%$ to $90 \%$ of total flavonoids in green tea, with epigallocatechin gallate (EGCG) being the most abundant catechin ( $48 \%-55 \%)$, followed by epigallocatechin (EGC) ( $9 \%-12 \%)$, epicatechin gallate (ECG) $(9 \%-12 \%)$, and epicatechin (EC) $(5 \%-7 \%)[19,23,24]$. One cup of GT (2.5 g of green tea leaves/200 mL of water) contains 150-200 mg of catechins, including 70-90 mg of EGCG $[17,19]$. However, the relative catechin content of GT is dependent on a number of factors, including the degree of fermentation in the production stage and how the infusion is prepared prior to consumption [1,17]. The main structural feature of GTCs (Figure 1) is a 2-phenylchromane skeleton, with substituted hydroxyl groups at the $3,5,7,3^{\prime}$, and $4^{\prime}$ positions $[23,25]$. Much of the proposed beneficial effect of GTCs is thought to be caused by the activity of these catechol hydroxyl groups, which serve as hydrogen donors and metal chelators [24]. Therefore, the proposed health benefits are primarily attributed to the functional properties of these groups. Additionally, observed improvements in blood glucose control, hypocholesterolemic effect, and blood pressure reduction can also be related to this structural anomaly, as well as various mechanisms of action within the biological system [19].<smiles>Oc1cc(O)c2c(c1)O[C@H](c1ccc(O)c(O)c1)[C@H](O)C2</smiles>

(a)

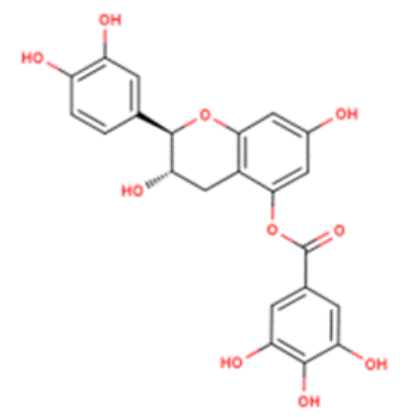

(c)<smiles>Oc1cc(O)c2c(c1)O[C@H](c1cc(O)c(O)c(O)c1)[C@H](O)C2</smiles>

(b)<smiles>O=C(O[C@H]1Cc2c(O)cc(O)cc2O[C@H]1c1cc(O)c(O)c(O)c1)c1cc(O)c(O)c(O)c1</smiles>

(d)

Figure 1. Chemical structures of green tea catechins: (a) Epicatechin (EC); (b) Epigallocatechin (EGC); (c) Epicatechin-3-gallate (ECG); (d) Epigallocatechin-3-gallate (EGCG) [26].

To date, only one study examining the effect of tea on CVD risk (hypertension, hypercholesterolemia, and dyslipidemia) has looked at both black and green tea [27]. This systematic review revealed that clinical trials investigating the dietary intervention of GTCs supplementation in high risk CVD individuals demonstrated a small decrease in diastolic and systolic blood pressure, and a potential for lowering total cholesterol after mid- to long-term consumption (three to six months) [27]. As there is a rising demand for tea globally, it could be argued that health effects from GT consumption in humans may have major beneficial implicationsand lead to additional improvements in health status. Although substantial evidence from in vitro and animal studies indicates that GT preparations inhibit development of CVD [20], the possible protective role of GT consumption against CVD in humans remains inconclusive. To date, a number of studies have examined the association between green tea consumption and mortality, but there are methodological issues-including, but not limited to, sample size — that have led to inconsistent results. 
Despite the variability of effect, with some studies finding conflicting outcomes [28-30], the majority of the current literature appears to support the positive therapeutic effect derived from GT consumption [1,9-15,31-34]. Furthermore, as tea consumption is high globally, it could be proposed that even modest health effects in humans may have major beneficial implications for global population health and reduction in CVD risk [21,35]. This is in alignment with recently published European data, regarding the prevention strategies against CVD, reporting that despite the decrease in CVD mortality within the last decade, there are significant differences between countries. Moreover, those who have persistent higher CVD mortality rates have paid less attention to various strategies concerning CVD risk factors and biomarkers [36].

Therefore, the aim of this systematic review was to determine and combine the effects of GTCs supplementation on CVD risk markers such as anthropometric aspects, blood pressure and related biomarkers. A secondary objective was to elucidate potential physiological mechanisms through which GTCs act and discuss its possible therapeutic benefits in the field of CVD prevention and risk reduction.

\section{Methods/Design}

The present systematic review protocol was planned, conducted, and reported in adherence with the PRISMA 2009 guidelines [37]. An electronic literature search was conducted using four databases: PubMed, The Cochrane Library, Web of Science and Scopus. Free text keywords were used to conduct the search. Medical subject headings (MeSH) were considered in the development of the search terms (Section 2.1). Titles, abstracts and methods were screened for relevance. Articles deemed relevant were selected for further consideration (Figure 2). The search strategy was piloted across each database to improve the effectiveness of the final search. The search was limited to human subjects, RCTs, and peer reviewed original research articles published in English between 1990, until the end of October 2015. It was beyond the scope of this review to include and examine sources from 'grey' literature.

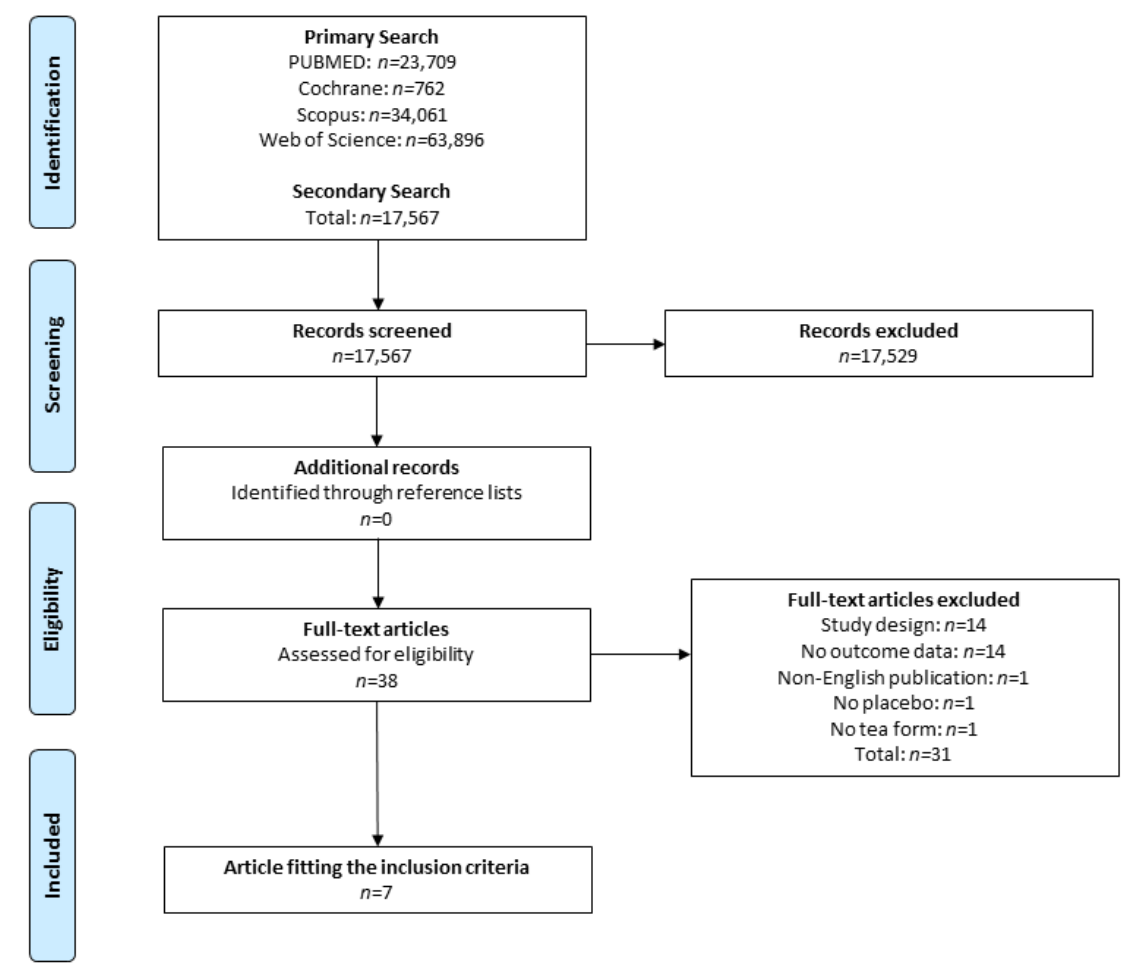

Figure 2. Schematic representation of the flow of information during the different phases of the systematic review. 


\subsection{Search Terminology}

The search terms used included: "green tea catechins", "green tea extract", "epigallocatechin gallate", "epigallocatechin", "epicatechin gallate", "epicatechin" AND "cardiovascular disease", "atherosclerosis" and "total cholesterol". These were combined using the Boolean operators AND as stated above, and OR between other terms. A hand search was undertaken of reference lists, with the intent to assure quality of the chosen articles.

\subsection{Selection Criteria and Data Extraction}

Studies were eligible for inclusion if the following applied: (1) they were RCTs, had a minimum sample size of ten healthy and/or diseased participants (including single or both genders); (2) they involved examination of any dietary supplement, consisting of GTCs or an individual catechin in the form of tea, compared against a placebo (3) adult participants aged $\geqslant 18$ years old; (4) reported markers of CVD (TG, TC, HDL-C, LDL-C, or BP (blood pressure)) at baseline and at the end of intervention. Animal trials and studies examining the effects of GT extract given in any other form than tea were excluded. Additionally, if multiple publications referred to the same results, the findings of the latest publication were included. More details on the outcomes of the exclusion criteria are further described in Section 3.1.

All papers identified from the initial electronic search process were imported into an EndNote library (version X7, Thomson Reuters), and duplicates were removed. Studies were selected based on the eligibility criteria as outlined above. Three investigators (S.O.L., E.N.G., and N.N.) independently screened the titles and abstracts of articles for eligibility to be included in the systematic review. If consensus was reached, ineligible articles were excluded and eligible articles were moved to the next stage (full-text review) in the process. If consensus was not reached, the article was moved to the next stage, in which the full text of the selected articles was evaluated to determine the eligibility for inclusion in the systematic review. Disagreements were resolved by discussion among the reviewers until a consensus was reached. In total, 38 articles were selected for full-text review and only seven articles fitted the inclusion criteria (Figure 2) and were included in this systematic review. The reason for excluding each study was recorded. At this stage, the reference lists of included studies were scanned, and if any relevant studies were identified, the full text was retrieved and reviewed for inclusion by all reviewers. Data extraction of included studies was completed by two independent reviewers (S.O.L. and E.N.G.) using a data extraction template. The template included the following: author; title; journal; year of publication; study setting; study design; study population; sample size; participant demographic characteristics; method used to assess markers of CVD.

\subsection{Outcomes}

The primary outcomes included in this systematic review on the effect of GTCs supplementation on CVD were responses of several biomarkers associated with CVD risk factors, including immunoradiometric assay (RIA) findings, TC, LDL-C, HDL-C TG glucose metabolism indices, such as fasting glucose, fasting insulin levels and inflammatory biomarkers, including $\mathrm{C}$-reactive protein (CRP) and Tumor Necrosis Factor- $\alpha$ (TNF- $\alpha$ ). Other investigated outcomes were blood pressure responses, including systolic (SBP) and diastolic blood pressure (DBP) and anthropometrical measurements including height, weight (wt), BMI, and WC.

\subsection{Data Analysis}

Each study was analyzed based on its merit and outlined inclusion criteria. These studies were appraised for their design, interventions, sample size, and the age and gender of the participants, outcome, and compliance measures. Study results were recorded as baseline and post intervention outcome values. Due to the heterogeneity of the study designs, settings, interventions, and outcomes, it was not possible to undertake a meaningful meta-analysis in this systematic review. 


\section{Results}

\subsection{Search in Literature}

The initial search resulted in a total of 122,428 articles, with a more specific secondary search identifying 17,567 articles. After screening secondary search article titles, abstracts, and methods, as well as removing irrelevant and duplicate items, the final number of articles was reduced down to 38, as presented in Figure 2. Of which, 30 were excluded on the basis of: study design $(n=16)$, missing outcome data $(n=14)$, and absence of placebo group $(n=1)$. The seven remaining studies [9-15] met the inclusion criteria (Table 1), with a cumulative total of 466 participants aged from 16 to 65 , with an average age of $47.7 \pm 9.2$ years (mean \pm SD). Five of the chosen studies [9-15] included participants of both gender, whilst the remaining three $[10,11,13]$ examined the effects of GT extract supplementation in females only. Furthermore, five of the chosen studies [9-13] investigated the effect of interventions on obese participants, two examined people with type 2 diabetes $[14,15]$, and one studied healthy individuals (Table 1).

Six of the studies examined the effects of GTE extract supplementation against a placebo while one study used a low dose of the GTE as a control. Six of the seven studies used opaque capsulated GT extract as a supplement, with an average daily supplement dose being $640 \mathrm{mg}$ /day (range 300-1500 mg/day) [9-13], while another study supplemented participants with a daily beverage containing $582.8 \mathrm{mg}$ GTCs [15]. The median trial length of the included studies was 12 weeks (range 12-16 weeks). The seven included studies were of random, double-blind, two-arm parallel, placebo-controlled study design. Furthermore, all of the chosen studies examined baseline and end level outcome changes for biochemical, anthropometric, and blood pressure outcomes. 
Table 1. Summary of effects of Green Tea Extracts (GTE) and Green Tea Catechins (GTC) in the selected human clinical trials [9-15].



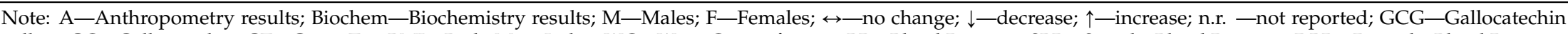
gallate; GC—Gallocatechin; GT—Green Tea; BMI—Body Mass Index; WC—Waist Circumference; BP—Blood Pressure; SBP-Systolic Blood Pressure; DBP—Diastolic Blood Pressure; TC-Total Cholesterol; LDL-C_Low Density Lipoprotein Cholesterol; HDL-C—High Density Lipoprotein Cholesterol; TG-Triglycerides. 


\subsection{Risk of Bias in Included Studies}

The risk of bias was independently assessed (N.N., S.O.K., and E.N.G.) with a majority of the chosen articles presenting with a low risk of bias for categories of selection, performance, detection, attrition, and reporting methods (Table 2). However, it should be noted that three studies $[11,14,15]$ were determined as being moderately at risk of selection bias. One study [13] showed moderate risk of attrition bias and another study [11] was deemed to have an unclear risk of bias, as attrition rate was not mentioned in the article. Additionally, all seven of the chosen studies showed an unclear risk of bias when assessing the blinding of outcome measurement results was assessed, with none disclosing relevant methodology.

Table 2. Risk of bias summary for studies included in this systematic review.

\begin{tabular}{|c|c|c|c|c|c|c|c|}
\hline Bias Category & $\begin{array}{l}\text { Bogdanski } \\
\text { et al. } \\
\text { (2012) [9] }\end{array}$ & $\begin{array}{l}\text { Chen et al. } \\
\text { (2015) [10] }\end{array}$ & $\begin{array}{l}\text { Diepvens } \\
\text { et al. } \\
\text { (2006) [11] }\end{array}$ & $\begin{array}{l}\text { Hsu et al. } \\
(2008)[13]\end{array}$ & $\begin{array}{l}\text { Hsu et al. } \\
\text { (2011) [12] }\end{array}$ & $\begin{array}{l}\text { Liu et al. } \\
\text { (2014) [14] }\end{array}$ & $\begin{array}{c}\text { Nagao } \\
\text { et al. (2009) } \\
{[15]}\end{array}$ \\
\hline $\begin{array}{l}\text { Random Sequence Generation } \\
\text { (selection bias) }\end{array}$ & Low & Low & Moderate & Low & Low & Moderate & Moderate \\
\hline $\begin{array}{l}\text { Blinding of participants and } \\
\text { personnel (performance bias). }\end{array}$ & Low & Low & Low & Low & Low & Low & Low \\
\hline $\begin{array}{l}\text { Blinding of outcome assessment } \\
\text { (detection bias) (mortality) }\end{array}$ & Unclear & Unclear & Unclear & Unclear & Unclear & Unclear & Unclear \\
\hline $\begin{array}{l}\text { Incomplete data addressed } \\
\text { (attrition bias) }\end{array}$ & Low & Low & Unclear & Moderate & Low & Low & Low \\
\hline Selective reporting (reporting bias) & Low & Low & Low & Low & Low & Low & Low \\
\hline Other bias & Low & Low & Low & Low & Low & Low & Low \\
\hline
\end{tabular}

\subsection{Results of the Selected Studies}

A study conducted by Bogdanski et al. (2012) [9] examined the effects of $379 \mathrm{mg} /$ day GTE dietary supplementation, in comparison to a placebo, on cardiovascular risk factors in 56 obese, hypertensive subjects for a three-month period ( 12 weeks). For all the measured outcomes, no significant differences were detected for the placebo group after three months of supplementation $(p>0.05)$ compared to baseline. In contrast, there was a significant reduction in SBP $(p=0.004), \operatorname{DBP}(p<0.001), \mathrm{TC}(p=0.009)$, LDL-C ( $p=0.011)$, TG $(p=0.004)$, fasting glucose $(p=0.016)$, fasting insulin $(p<0.001)$, HOMA-IR $(p=0.009)$, CRP $(p<0.001)$, TNF- $\alpha(p<0.001)$, and total antioxidant status (TAS) $(p<0.001)$ among the GTCs-treated individuals. Moreover, the three-month supplementation of GTCs was associated with significant decrease in SBP $(p<0.001)$, DBP $(p<0.001)$, TC $(p<0.001)$, LDL-C $(p=0.022)$, TG $(p<0.001)$, fasting insulin serum levels $(p=0.005)$, homeostatic model assessment of insulin resistance HOMA-IR $(p=0.004)$, TNF- $\alpha(p<0.001)$, and CRP $(p<0.001)$, and a significant increase in HDL-C $(p=0.023)$ and TAS $(p<0.001)$ compared to the placebo. The study evaluated the effect of GTCs supplementation on a range of CVD risk factors, including lipid profile, inflammatory markers, and antioxidant capacity. This revealed that there are a range of favorable effects of GTCs supplementation on CVD risk. However, the aforementioned study did not include people with diabetes, who have an increased CVD risk, and therefore this weakens the potential generalization of its findings.

Chen et al. (2015) [10] evaluated the effect of a high daily dosage of $1500 \mathrm{mg}$ GTE dietary supplementation for 12 weeks on the body weight and the lipid and hormonal profile of 77 women with abdominal obesity in Taipei. At the end of the intervention period, both groups had decreased the WC as compared to their baseline measurements (GTE group $p=0.023$ vs. placebo group $p=0.017$ ), but only the GTE group had decreased TC $(p=0.005)$ and LDL-C levels $(p=0.006)$ after the 12-week treatment. No differences were detected for the other CVD biomarkers measured (all $p>0.05$ ). Moreover, a statistically significant, but not clinically relevant, weight loss was reported for the GTE group only $(-0.9 \mathrm{~kg}, p=0.018)$. In contrast to the placebo, the 12-week GTE supplement intake led to a significant decrease in TC $(p=0.031)$ and LDL levels $(p=0.049)$, but no other differences were 
reported (all $p>0.05$ ). The study recruited only females, thus, these findings cannot be extrapolated to the general population.

A study by Diepvens et al. (2006) [11] recruited 46 healthy overweight females. This study observed the effects of GTE intervention for 87 days (12.4 weeks), while participants were on a low-energy diet. This study evaluated the effects of GT extract on metabolic parameters and weight loss in the intervention group in comparison to a placebo capsule administered to the control group. The placebo group showed significant reductions in all the anthropometric outcome measures (wt, BMI, WC, all $p<0.01)$, as well as in SBP $(p<0.05)$, TC $(p<0.05)$, HDL-C $(p<0.05)$, and TG $(p<0.05)$ levels. The GTE group showed a significant reduction in all anthropometric outcome measures (wt, BMI, WC all $p<0.01)$, as well as SBP $(p<0.01)$, DBP $(p<0.05)$, TC $(p<0.05)$, and HDL-C $(p<0.05)$. Unfortunately, a clear comparison was not presented between the two arms of the study, thus, it remains unclear whether the GTE was better/worse or similar to the placebo in terms of weight loss and metabolic parameters in addition to the typical low-energy diet plus placebo.

A study by Hsu et al. (2008) [13] investigated the effects of a 12-week GTE dietary supplementation in 78 obese, but otherwise healthy, females who visited an outpatient clinic in Taipei. There were no significant changes revealed in outcome measures (anthropometric characteristics, fasting biomarkers related to CVD, and hormones related to glucose metabolism) between the intervention and the placebo group after 12 weeks. This is one of the few studies which used and reported statistically appropriate comparisons between the two treatment groups. The study only evaluated the effect of GT intervention in obese females. Therefore, these findings cannot be extrapolated to the general population.

Another study by Hsu et al. (2011) [12] examined the effects of decaffeinated GTE supplemented for 16 weeks in 68 obese Chinese participants who had been diagnosed with type 2-diabetes. The authors presented univariate comparisons for the percentage reduction in the outcome variables. All the measured variables (anthropometric indices, arterial blood pressure, glucose metabolism markers, and CVD related biomarkers) did not differ significantly between the two subject groups $(p>0.05)$.

A study by Liu et al. (2014) [14] evaluated the effects of GTE supplementation over the course of 16 weeks on the lipid profiles of 102 subjects diagnosed with type 2 diabetes and dyslipidemia; this study was also located in an outpatient clinic in Taipei. As revealed by the 'within-groups analysis', the placebo group did not show significant changes in anthropometric (wt: $p=0.69$; BMI: $p=0.54$; WC: $p=0.69)$, SBP $(p=0.38)$, and biochemical measures (TC: $p=0.89$; LDL-C: $p=0.48$; HDL-C: $p=0.94$; TG: $p=0.38$ ) after the trial period, although DBP was found to have a significant reduction $(p=0.05)$. The decaffeinated GTCs group revealed favorable indicative changes in weight $(p=0.09)$, $\operatorname{BMI}(p=0.06)$, TGs $(p=0.03)$, and HDL-C $(p=0.04)$, with non-significant changes in DBP $(p=0.68)$, TC $(p=0.67), \operatorname{SBP}(p=0.48)$, and LDL-C $(p=0.55)$. However, when the variations in the aforementioned parameters were evaluated between the two subject groups, no significant differences were found. Thus, the authors claimed that the supplement did not offer any decrease in the participants' lipids, glucose, or weight parameters.

A multi-centered study by Nagao et al. (2009) [15] explored the effects of a catechin-rich beverage on 52 individuals diagnosed with type 2 diabetes over a period of 12 weeks. No significant changes were observed in the control group (wt, BMI, WC, SBP, DBP, TC, LDL-C, HDL-C, TG: $p>0.05$ ). The GTE supplemented group observed a significant reduction in WC $(p<0.05)$ and TC $(p<0.05)$. With regards to the differences between the two subject groups, the intervention group had a significantly higher insulin secretion after 12-weeks of treatment $(p<0.05)$, this observation was robust after adjusting for waist circumference. This study revealed an independent association of catechin intake and insulin secretion in diabetic subjects, which was not dependent on abdominal obesity parameters.

\section{Discussion}

Preventive approaches to health and lifestyle related diseases have emerged as an area of increasing interest in recent years, primarily in response to economic and societal burden attributed to 
ageing populations. Interest in nutritional approaches including the use of dietary supplements such as the widely available, accessible, and affordable GT as a potentially cardio- and vasculoprotective agent has grown rapidly amongst consumer groups and the scientific community globally.

Polyphenolic compounds contained in GT can offer protective effects against CVD by inducing antioxidative, lipid-lowering, anti-hypertensive, anti-obesity, anti-thrombogenic, and anti-inflammatory effects [38]. Importantly, the systemic absorption of GTCs incorporated within the GTE and even individual catechins, such as EGCG, is affected by several factors, including the type and quantity of the food consumed at the same time [39] and the exposure to biological fluids (gastric, pancreatic, and biliary fluids) prior to reaching the site of absorption. These factors can significantly influence the absorption and bioavailability of the GTCs in human trials. The studies outlined in this review have demonstrated some of the putative cardiovascular protective properties that GTCs may have on the lowering of body weight, arterial blood pressure, and plasma abnormalities in biomarkers commonly seen in individuals who are prone to developing a serious CVD-related illness in the future. Beneficial effects were observed when GTE was supplemented at levels between 300 and $1500 \mathrm{mg} /$ day (total GTCs 208-1344 mg/day), roughly in line with previous literature, which had suggested that $540 \mathrm{mg}$ of pure EGCG (between 5 and 10 cups of green tea [39]) was the optimal daily requirement for prevention of CVD risk factors [40]. Furthermore, the duration of the studies was also considered in the present systematic review, as significant sustained lowering of the CVD risk biomarkers were more likely to be seen in studies conducted over at least 12 weeks of supplementation [9-15]. Although the current evidence base appears to be varied, the studies reviewed identified some benefits of GTCs on lowering the CVD risk.

The study by Chen et al. [10] proposed that daily supplementation of GTCs significantly decreased body weight, BMI, and WC, which are variables readily associated with CVD pathogenesis and relevant comorbidities. However, the utility of this data is compromised by the limited statistical approach which did not compare the effect of the placebo with the changes seen with GTE dietary supplementation. Nonetheless, the results appeared to be consistent with previous literature that made this observation [12,17,34]. A study by Maki et al. [41,42] proposed that weight loss by GTCs supplementation is induced by influences on energy expenditure, fat oxidation promotion, modification of appetite, and a decreased nutrient absorption. Moreover, GTCs are thought to inhibit the enzyme catechol $O$-methyltransferase and its degradative effects on noradrenaline (NA), thereby prolonging the effect of NA in the synaptic cleft and increasing energy expenditure through this pathway [42]. Additionally, findings in previous studies proposed that this specific mechanism has the potential to stimulate lipolysis in peripheral adipose and skeletal muscle tissues, thereby upregulating hepatic lipid metabolism that causes improvement in the fatty acid oxidation rate and metabolism [43]. However, anthropometric benefits were not universally observed across all GTE supplementation trials in this review $[9,12-14]$ (Table 1). This inconsistency of results could potentially be attributed to differences in study designs and choice of participants. Another study by Chen et al. [11] recorded changes over a period of 12 weeks (wt: $p=0.025$; BMI: $p=0.018$; WC: $p=0.023$ ). Consequentially, this further indicates that duration of studies is as important as the dosage of the active ingredient when considering the intervention design, which constitutes an important parameter when addressing changes in anthropometry. Thus, it could be argued that the two-week follow-up period is not sufficiently long enough for this outcome.

The study by Bogdanski et al. [9] demonstrated that the daily consumption of a high-dose of GTE (379 mg/day) over three months significantly decreased SBP and DBP ( $p=0.04$ and $p<0.001$, respectively) in overweight females. Hypotensive effects have also been observed in other trials $[9,13,14,44]$, with the suggested mechanism of action being vasodilation in response to the stimulation and amplified production of nitric oxide by the vascular endothelium. This is in agreement with the data from a study in an animal model, the stroke-prone, spontaneously hypertensive rats, in which GTCs were shown to significantly lower SBP and DBP [45]. The authors suggested that a reduction in the formation of reactive oxygen species in the vasculature and an enhanced endothelium 
relaxation of the aorta in these rats could be the cause of the hypotensive effects of the GTCs. A previous meta-analysis by Taubert et al. [46] indicated that green and black tea had no significant effect on BP, whilst another by Liu et al. [14] determined that GT could result in significant reductions of SBP and DBP. However, Taubert et al. [46] 2007 findings were less conclusive, with a lower total subject pool $(n=173)$ for a meta-analysis and the average study duration was also short (two weeks). Liu et al.'s [14] 2014 review concluded that GT consumption could decrease BP; however, they suggested that optimum results only occurred after long term ( $\geqslant 12$ weeks) intervention. Despite these conclusions, improved BP status was not reflected in all the studies chosen for the present systematic review, with no significant changes observed even in trials that ran for more than 16 weeks $[12,14]$. Consequently, these findings warrant further investigation, with particular attention paid to the study design, the sample size, and the participants' inclusion criteria.

The study by Hsu et al. [13] found significant reductions in biochemical markers associated with atherosclerosis, metabolic syndrome, and CVD pathogenesis. This finding was in accordance with other reports in the literature, where GTCs have been shown to prolong lag time, inhibit formation of oxidized cholesterol and decrease the linoleic acid and arachidonic acid concentrations [47], and to have hypocholesterolemic and hypolipidemic effects $[10,11,16,17]$. A study by Yang and Koo [48] using an animal model proposed that the hypocholesterolemic effect of GTCs was suggestive of increased fecal bile and cholesterol excretion in studied rodents. This is not the only potential mechanism, since others have also suggested the cholesterol-lowering effects of GT, including reducing capacity of hepatic cholesterol concentration and upregulation of hepatic LDL receptors [49-51]. The hypolipidemic effect of GTCs consumption is attributed to reduced intestinal absorption and decreased digestibility of cholesterol and dietary fats [52-54]. Additionally, EGCG has been identified to possess the potential to inhibit pancreatic lipase, contributing to the development of natural lipase inhibitors to prevent human obesity and dyslipidemia [55]. In particular, significant LDL-C reduction $[9,10,13,15]$ is a remarkable finding, as LDL-C promotes chronic inflammation of arterial blood vessels by white blood cells [56]. In addition, GTCs are expected to prevent this vascular inflammation by suppressing leukocyte adhesion ability to the endothelium, thereby indicating the potential to inhibit progression of atherosclerotic lesions and thrombogenesis [38] However, despite these findings, the reviewed studies showed varying degrees of hypocholesterolemic and hypolipidemic activity in participants, with some studies indicating insignificant change for both parameters in the group supplemented with GTCs $[11,12,14]$. This finding is possibly attributed to the differing health conditions and statuses of the participants recruited, differences in study designs [1], and the effect of food consumption on catechins systemic absorption [39].

Studies by Hsu et al. [13] and Liu et al. [14] identified statistically significant changes in within-group analyses, despite having no significant differences in variable outcomes between the GTCs supplemented and placebo groups, whereas others, including Chen et al. [10] and Diepvens et al. [11], either did not undertake between-group analysis or did not fully report the data. These changes were noted in a reduction in WC [13], and significant changes in TC, HDL, and TG [14], respectively. Hsu et al. [13] suggested that the significant within-group reduction in WC is possibly attributed to changes in body composition or weight redistribution, although no significant changes in BMI were observed. Liu et al. [14] proposed that increased circulating levels of the satiety-related hormone glucagon-like peptide 1 (GLP-1) was the cause of the noted beneficial biochemical outcomes found in the within-group analysis. Some authors have previously indicated a significant interaction between circulating GLP-1, HDL, and TG, but not anthropometry [57], which is consistent in trials with rabbits $[50,58,59]$.

A limitation faced when analyzing articles for this systematic review was that there were some discrepancies in the study design of the seven studies, including inadequate statistical approaches and reporting different participant inclusion criteria. The length of trial periods ranged from twelve to sixteen weeks, and the dose of GTCs given to study participants ranged from 46 to $1500 \mathrm{mg} /$ day. Furthermore, the participants recruited included healthy volunteers, obese, and individuals with type 2 diabetes. These listed factors are critical parameters in determining the results of the trials and therefore, absolute comparison between them could not be performed under the context of this 
systematic review. Additionally, all of the selected articles did not examine the long-term preventive effects of GTCs supplementation on CVD risk and hard endpoints (>12 months). Moreover, there was a near universal lack of adjustment for potential confounders within the reviewed studies, which is an important drawback when addressing a multifactorial disease such as CVD. These limitations highlight the need for further scientifically rigorous trials with bigger samples using robust statistical approaches and longer follow-up periods in order to observe long-term association of GTCs consumption and CVD risk and pathogenesis.

\section{Conclusions}

In conclusion, the published papers reviewed in this systematic review indicate that GTCs possesses some potentially cardio- and vascular-protective properties, which may be useful for reducing CVD risk using a low-cost, naturally found product. Published studies chosen for this systematic review have demonstrated the effects of GTCs supplementation on one or more of the CVD risk factors. Although the current findings suggest considerable benefit can be achieved from a high daily dose of GTCs consumption, further research is necessary to explore an absolute optimal dosage and trial duration. Furthermore, this should be explored in differing disease-specific populations, as well as in the general population. It is therefore anticipated that this review will generate interest into the long-term consumption of tea catechins and its beneficial effects in reducing CVD risk in predisposed individuals.

Acknowledgments: This research was supported by the Faculty of Health Research Support Funding, University of Canberra, Canberra, ACT, Australia.

Author Contributions: N.N., P.D.R., and J.K. conceived designed the study; S.O.L. and E.N.G. performed the searches; N.N., S.O.L, E.N.G., and A.M. analyzed the data; D.M. and J.T. contributed critical analysis; S.O.L., E.N.G., and N.N. wrote the paper. All authors have contributed substantially to the work reported.

Conflicts of Interest: The authors declare no conflict of interest.

\section{Abbreviations}

The following abbreviations are used in this manuscript:

\begin{tabular}{ll} 
CVD & Cardiovascular Disease \\
BP & Blood Pressure \\
LDL-C & Low Density Lipoprotein Cholesterol \\
HDL-C & High Density Lipoprotein Cholesterol \\
TC & Total Cholesterol \\
WC & Waist Circumference \\
BMI & Body Mass Index \\
GT & Green Tea \\
GTC & Green Tea Catechins \\
EGCG & Epigallocatechin Gallate \\
EGC & Epigallocatechin \\
ECG & Epicatechin Gallate \\
EC & Epicatechin \\
PRISMA & Preferred Reporting Items for Systematic Reviews and Meta-Analyses \\
RIA & Immunoradiometric Assay \\
TNF- $\alpha$ & Tumor Necrosis Factor- $\alpha$ \\
CRP & C-Reactive Protein \\
SBP & Systolic Blood Pressure \\
DBP & Diastolic Blood Pressure \\
TG & Triglycerides \\
HOMA-IR & Homeostatic Model Assessment for Insulin Resistance \\
TAS & Total Antioxidant Status \\
NA & Noradrenaline \\
GLP-1 & Glucagon-Like Peptide 1 \\
wt & Weight \\
\hline
\end{tabular}




\section{References}

1. Basu, A.; Lucas, E.A. Mechanisms and effects of green tea on cardiovascular health. Nutr. Rev. 2007, 65, 361-375. [CrossRef] [PubMed]

2. WHO. Cardiovascular Disease. Available online: http://www.who.int/cardiovascular_diseases/en/ (accessed on 20 April 2016).

3. Poirier, P.; Giles, T.D.; Bray, G.A.; Hong, Y.; Stern, J.S.; Pi-Sunyer, F.X.; Eckel, R.H. Obesity and cardiovascular disease: Pathophysiology, evaluation, and effect of weight loss. Arterioscler. Thromb. Vasc. Biol. 2006, 26, 968-976. [CrossRef] [PubMed]

4. Board, J. Joint British Societies' consensus recommendations for the prevention of cardiovascular disease (jbs3). Heart 2014, 100, ii1-ii67.

5. Parikh, R.M.; Mohan, V. Changing definitions of metabolic syndrome. Indian J. Endocrinol. Metab. 2012, 16, 7-12. [CrossRef] [PubMed]

6. Joffres, M.; Falaschetti, E.; Gillespie, C.; Robitaille, C.; Loustalot, F.; Poulter, N.; McAlister, F.A.; Johansen, H.; Baclic, O.; Campbell, N. Hypertension prevalence, awareness, treatment and control in national surveys from england, the USA and Canada, and correlation with stroke and ischaemic heart disease mortality: A cross-sectional study. BMJ Open 2013, 3, e003423. [CrossRef] [PubMed]

7. Nathan, D.M. Diabetes: Advances in diagnosis and treatment. JAMA 2015, 314, 1052-1062. [CrossRef] [PubMed]

8. Yudkin, J.S.; Stehouwer, C.; Emeis, J.; Coppack, S. C-reactive protein in healthy subjects: Associations with obesity, insulin resistance, and endothelial dysfunction a potential role for cytokines originating from adipose tissue? Arterioscler. Thromb. Vasc. Biol. 1999, 19, 972-978. [CrossRef] [PubMed]

9. Bogdanski, P.; Suliburska, J.; Szulinska, M.; Stepien, M.; Pupek-Musialik, D.; Jablecka, A. Green tea extract reduces blood pressure, inflammatory biomarkers, and oxidative stress and improves parameters associated with insulin resistance in obese, hypertensive patients. Nutr. Res. 2012, 32, 421-427. [CrossRef] [PubMed]

10. Chen, I.J.; Liu, C.Y.; Chiu, J.P.; Hsu, C.H. Therapeutic effect of high-dose green tea extract on weight reduction: A randomized, double-blind, placebo-controlled clinical trial. Clin. Nutr. 2015, 35, 392-399. [CrossRef] [PubMed]

11. Diepvens, K.; Kovacs, E.M.; Vogels, N.; Westerterp-Plantenga, M.S. Metabolic effects of green tea and of phases of weight loss. Physiol. Behav. 2006, 87, 185-191. [CrossRef] [PubMed]

12. Hsu, C.H.; Liao, Y.L.; Lin, S.C.; Tsai, T.H.; Huang, C.J.; Chou, P. Does supplementation with green tea extract improve insulin resistance in obese type 2 diabetics? A randomized, double-blind, and placebo-controlled clinical trial. Altern. Med. Rev. J. Clin. Ther. 2011, 16, 157-163. [CrossRef] [PubMed]

13. Hsu, C.H.; Tsai, T.H.; Kao, Y.H.; Hwang, K.C.; Tseng, T.Y.; Chou, P. Effect of green tea extract on obese women: A randomized, double-blind, placebo-controlled clinical trial. Clin. Nutr. 2008, 27, 363-370. [CrossRef] [PubMed]

14. Liu, C.Y.; Huang, C.J.; Huang, L.H.; Chen, I.J.; Chiu, J.P.; Hsu, C.H. Effects of green tea extract on insulin resistance and glucagon-like peptide 1 in patients with type 2 diabetes and lipid abnormalities: A randomized, double-blinded, and placebo-controlled trial. PLoS ONE 2014, 9, e91163. [CrossRef] [PubMed]

15. Nagao, T.; Meguro, S.; Hase, T.; Otsuka, K.; Komikado, M.; Tokimitsu, I.; Yamamoto, T.; Yamamoto, K. A catechin-rich beverage improves obesity and blood glucose control in patients with type 2 diabetes. Obesity 2009, 17, 310-317. [CrossRef] [PubMed]

16. Meldrum, B. Glutamate as a neurotransmitter in the brain: Review of physiology and pathology. J. Nutr. 2000, 130 (Suppl. S4), 1007S-1015S. [PubMed]

17. Cabrera, C.; Artacho, R.; Gimenez, R. Beneficial effects of green tea-A review. J. Am. Coll. Nutr. 2006, 25, 79-99. [CrossRef] [PubMed]

18. Johnson, R.; Bryant, S.; Huntley, A.L. Green tea and green tea catechin extracts: An overview of the clinical evidence. Maturitas 2012, 73, 280-287. [CrossRef] [PubMed]

19. Murray, M.; Walchuk, C.; Suh, M.; Jones, P.J. Green tea catechins and cardiovascular disease risk factors: Should a health claim be made by the united states food and drug administration? Trends Food Sci. Technol. 2015, 41, 188-197. [CrossRef]

20. Chacko, S.M.; Thambi, P.T.; Kuttan, R.; Nishigaki, I. Beneficial effects of green tea: A literature review. Chin. Med. 2010. [CrossRef] [PubMed] 
21. Kuriyama, S.; Shimazu, T.; Ohmori, K.; Kikuchi, N.; Nakaya, N.; Nishino, Y.; Tsubono, Y.; Tsuji, I. Green tea consumption and mortality due to cardiovascular disease, cancer, and all causes in Japan: The ohsaki study. JAMA 2006, 296, 1255-1265. [CrossRef] [PubMed]

22. Keating, B.; Lindstrom, A.; Lynch, M.-E.; Blumenthal, M. Sales of tea \& herbal tea increase $5.9 \%$ in united states in 2013. In 2014 Tea Sales in Track to Set a Record; HerbalEGram: Austin, TX, USA, 2014.

23. Legeay, S.; Rodier, M.; Fillon, L.; Faure, S.; Clere, N. Epigallocatechin gallate: A review of its beneficial properties to prevent metabolic syndrome. Nutrients 2015, 7, 5443-5468. [CrossRef] [PubMed]

24. Watson, R.R.; Preedy, V.R.; Zibadi, S. Polyphenols in Human Health and Disease; Elsevier: London, UK, 2014; p. 3 .

25. Naumovski, N. Bioactive composition of plants and plant foods. In Plant Bioactive Compounds for Pancreatic Cancer Prevention and Treatment; Scarlett, C.J., Vuong, Q.V., Eds.; Nova Publishers: New York, NY, USA, 2015; p. 322.

26. Kim, S.; Thiessen, P.A.; Bolton, E.E.; Chen, J.; Fu, G.; Gindulyte, A.; Han, L.; He, J.; He, S.; Shoemaker, B.A.; et al. Pubchem substance and compound databases. Nucleic Acids Res. 2016, 44, D1202-D1213. [CrossRef] [PubMed]

27. Hartley, L.; Flowers, N.; Holmes, J.; Clarke, A.; Stranges, S.; Hooper, L.; Rees, K. Green and black tea for the primary prevention of cardiovascular disease. Cochrane Database Syst. Rev. 2013. [CrossRef]

28. Engler, M.B.; Engler, M.M.; Chen, C.Y.; Malloy, M.J.; Browne, A.; Chiu, E.Y.; Kwak, H.K.; Milbury, P.; Paul, S.M.; Blumberg, J.; et al. Flavonoid-rich dark chocolate improves endothelial function and increases plasma epicatechin concentrations in healthy adults. J. Am. Coll. Nutr. 2004, 23, 197-204. [CrossRef] [PubMed]

29. Klaunig, J.E.; Xu, Y.; Han, C.; Kamendulis, L.M.; Chen, J.; Heiser, C.; Gordon, M.S.; Mohler, E.R., 3rd. The effect of tea consumption on oxidative stress in smokers and nonsmokers. Proc. Soc. Exp. Biol. Med. 1999, 220, 249-254. [CrossRef] [PubMed]

30. Princen, H.M.; van Duyvenvoorde, W.; Buytenhek, R.; Blonk, C.; Tijburg, L.B.; Langius, J.A.; Meinders, A.E.; Pijl, H. No effect of consumption of green and black tea on plasma lipid and antioxidant levels and on ldl oxidation in smokers. Arterioscler. Thromb. Vasc. Biol. 1998, 18, 833-841. [CrossRef] [PubMed]

31. Curtis, P.J.; Sampson, M.; Potter, J.; Dhatariya, K.; Kroon, P.A.; Cassidy, A. Chronic ingestion of flavan-3-ols and isoflavones improves insulin sensitivity and lipoprotein status and attenuates estimated 10-year cvd risk in medicated postmenopausal women with type 2 diabetes: A 1-year, double-blind, randomized, controlled trial. Diabetes Care 2012, 35, 226-232. [CrossRef] [PubMed]

32. Inami, S.; Takano, M.; Yamamoto, M.; Murakami, D.; Tajika, K.; Yodogawa, K.; Yokoyama, S.; Ohno, N.; Ohba, T.; Sano, J.; et al. Tea catechin consumption reduces circulating oxidized low-density lipoprotein. Int. Heart J. 2007, 48, 725-732. [CrossRef] [PubMed]

33. Liu, G.; Mi, X.N.; Zheng, X.X.; Xu, Y.L.; Lu, J.; Huang, X.H. Effects of tea intake on blood pressure: A meta-analysis of randomised controlled trials. Br. J. Nutr. 2014, 112, 1043-1054. [CrossRef] [PubMed]

34. Nogueira, L.P.; Knibel, M.P.; Torres, M.R.; Nogueira Neto, J.F.; Sanjuliani, A.F. Consumption of high-polyphenol dark chocolate improves endothelial function in individuals with stage 1 hypertension and excess body weight. Int. J. Hypertens. 2012. [CrossRef] [PubMed]

35. Bhardwaj, P.; Khanna, D. Green tea catechins: Defensive role in cardiovascular disorders. Chin. J. Nat. Med. 2013, 11, 345-353. [CrossRef]

36. Nichols, M.; Townsend, N.; Scarborough, P.; Rayner, M. Cardiovascular disease in Europe 2014: Epidemiological update. Eur. Heart J. 2014, 35, 2950-2959. [CrossRef] [PubMed]

37. Moher, D.; Liberati, A.; Tetzlaff, J.; Altman, D.G. Preferred reporting items for systematic reviews and meta-analyses: The prisma statement. J. Clin. Epidemiol. 2009, 62, 1006-1012. [CrossRef] [PubMed]

38. Babu, P.V.; Liu, D. Green tea catechins and cardiovascular health: An update. Curr. Med. Chem. 2008, 15, 1840-1850. [CrossRef] [PubMed]

39. Naumovski, N.; Blades, B.L.; Roach, P.D. Food inhibits the oral bioavailability of the major green tea antioxidant epigallocatechin gallate in humans. Antioxidants 2015, 4, 373-393. [CrossRef] [PubMed]

40. Nakachi, K.; Matsuyama, S.; Miyake, S.; Suganuma, M.; Imai, K. Preventive effects of drinking green tea on cancer and cardiovascular disease: Epidemiological evidence for multiple targeting prevention. BioFactors 2000, 13, 49-54. [CrossRef] [PubMed] 
41. Maki, K.C.; Reeves, M.S.; Farmer, M.; Yasunaga, K.; Matsuo, N.; Katsuragi, Y.; Komikado, M.; Tokimitsu, I.; Wilder, D.; Jones, F.; et al. Green tea catechin consumption enhances exercise-induced abdominal fat loss in overweight and obese adults. J. Nutr. 2009, 139, 264-270. [CrossRef] [PubMed]

42. Borchardt, R.T.; Huber, J.A. Catechol o-methyltransferase. 5. Structure-activity relationships for inhibition by flavonoids. J. Med. Chem. 1975, 18, 120-122. [CrossRef] [PubMed]

43. Rains, T.M.; Agarwal, S.; Maki, K.C. Antiobesity effects of green tea catechins: A mechanistic review. J. Nutr. Biochem. 2011, 22, 1-7. [CrossRef] [PubMed]

44. Brown, A.L.; Lane, J.; Coverly, J.; Stocks, J.; Jackson, S.; Stephen, A.; Bluck, L.; Coward, A.; Hendrickx, H. Effects of dietary supplementation with the green tea polyphenol epigallocatechin-3-gallate on insulin resistance and associated metabolic risk factors: Randomized controlled trial. Br. J. Nutr. 2009, 101, 886-894. [CrossRef] [PubMed]

45. Negishi, H.; Xu, J.W.; Ikeda, K.; Njelekela, M.; Nara, Y.; Yamori, Y. Black and green tea polyphenols attenuate blood pressure increases in stroke-prone spontaneously hypertensive rats. J. Nutr. 2004, 134, 38-42. [PubMed]

46. Taubert, D.; Roesen, R.; Schomig, E. Effect of cocoa and tea intake on blood pressure: A meta-analysis. Arch. Int. Med. 2007, 167, 626-634. [CrossRef] [PubMed]

47. Osada, K.; Takahashi, M.; Hoshina, S.; Nakamura, M.; Nakamura, S.; Sugano, M. Tea catechins inhibit cholesterol oxidation accompanying oxidation of low density lipoprotein in vitro. Comp. Biochem. Physiol. Toxicol. Pharmacol. 2001, 128, 153-164. [CrossRef]

48. Yang, T.T.; Koo, M.W. Hypocholesterolemic effects of chinese tea. Pharmacol. Res. 1997, 35, 505-512. [CrossRef] [PubMed]

49. Maron, D.J.; Lu, G.P.; Cai, N.S.; Wu, Z.G.; Li, Y.H.; Chen, H.; Zhu, J.Q.; Jin, X.J.; Wouters, B.C.; Zhao, J. Cholesterol-lowering effect of a theaflavin-enriched green tea extract: A randomized controlled trial. Arch. Int. Med. 2003, 163, 1448-1453. [CrossRef] [PubMed]

50. Bursill, C.A.; Abbey, M.; Roach, P.D. A green tea extract lowers plasma cholesterol by inhibiting cholesterol synthesis and upregulating the ldl receptor in the cholesterol-fed rabbit. Atherosclerosis 2007, 193, 86-93. [CrossRef] [PubMed]

51. Bursill, C.A.; Roach, P.D. A green tea catechin extract upregulates the hepatic low-density lipoprotein receptor in rats. Lipids 2007, 42, 621-627. [CrossRef] [PubMed]

52. Chan, P.T.; Fong, W.P.; Cheung, Y.L.; Huang, Y.; Ho, W.K.; Chen, Z.Y. Jasmine green tea epicatechins are hypolipidemic in hamsters (mesocricetus auratus) fed a high fat diet. J. Nutr. 1999, 129, 1094-1101. [PubMed]

53. Friedrich, M.; Petzke, K.J.; Raederstorff, D.; Wolfram, S.; Klaus, S. Acute effects of epigallocatechin gallate from green tea on oxidation and tissue incorporation of dietary lipids in mice fed a high-fat diet. Int. J. Obes. 2012, 36, 735-743. [CrossRef] [PubMed]

54. Hasegawa, N.; Yamda, N.; Mori, M. Powdered green tea has antilipogenic effect on zucker rats fed a high-fat diet. Phytother. Res. 2003, 17, 477-480. [CrossRef] [PubMed]

55. Grove, K.A.; Sae-tan, S.; Kennett, M.J.; Lambert, J.D. (-)-Epigallocatechin-3-gallate inhibits pancreatic lipase and reduces body weight gain in high fat-fed obese mice. Obesity 2012, 20, 2311-2313. [CrossRef] [PubMed]

56. Long, A.N.; Dagogo-Jack, S. Comorbidities of diabetes and hypertension: Mechanisms and approach to target organ protection. J. Clin. Hypertens. 2011, 13, 244-251. [CrossRef] [PubMed]

57. Yamaoka-Tojo, M.; Tojo, T.; Takahira, N.; Matsunaga, A.; Aoyama, N.; Masuda, T.; Izumi, T. Elevated circulating levels of an incretin hormone, glucagon-like peptide-1, are associated with metabolic components in high-risk patients with cardiovascular disease. Cardiovasc. Diabetol. 2010. [CrossRef] [PubMed]

58. Bursill, C.; Roach, P.D.; Bottema, C.D.; Pal, S. Green tea upregulates the low-density lipoprotein receptor through the sterol-regulated element binding protein in hepg2 liver cells. J. Agric. Food Chem. 2001, 49, 5639-5645. [CrossRef] [PubMed]

59. Bursill, C.A.; Roach, P.D. Modulation of cholesterol metabolism by the green tea polyphenol (-)-epigallocatechin gallate in cultured human liver (hepg2) cells. J. Agric. Food Chem. 2006, 54, 1621-1626. [CrossRef] [PubMed]

(C) 2016 by the authors; licensee MDPI, Basel, Switzerland. This article is an open access article distributed under the terms and conditions of the Creative Commons Attribution (CC-BY) license (http://creativecommons.org/licenses/by/4.0/). 